\title{
FALANDO FRANCAMENTE: UMA LEITURA BAKHTINIANA DO CONCEITO DE "INGLÊS COMO LÍNGUA FRANCA" NO COMPONENTE CURRICULAR LÍNGUA INGLESA DA BNCC
}

\section{FRANKLY SPEAKING: READING THE CONCEPT OF "ENGLISH AS A LINGUA FRANCA" WITHIN THE NATIONAL COMMON CORE CURRICULUM IN LIGHT OF BAKHTINIAN THOUGHT}

Ana Paula Martinez Duboc Universidade de São Paulo, São Paulo, São Paulo, Brasil

Resumo: O presente artigo visa analisar o conceito de inglês como língua franca (ILF) que fundamenta o Componente Curricular Língua Inglesa da Base Nacional Comum Curricular Ensino Fundamental (BNCC). Para tanto, inicia com a apresentação das principais definições deste conceito polêmico e polissêmico, com ênfase para as primeiras teorizações da década de 80 no âmbito das pesquisas internacionais de modo a culminar nas recentes reconceituações na produção científica brasileira, o que chamo aqui de ILF made in Brazil, evidenciando a natureza refratária, dialogizante e heteroglóssica do signo segundo Bakhtin. Após tecer considerações acerca desses conceitos, o artigo analisa a presença do conceito de ILF no Componente Curricular Língua Inglesa da BNCC, atestando a existência de um conflito epistemológico quando texto introdutório e quadros de conteúdos são confrontados, conflito posto na medida em que a natureza fluida e situada atribuída aos recentes debates sobre ILF entra em choque com a normatividade, consenso e padronização usualmente postos por um currículo nacional comum. À moda bakhtiniana, o artigo conclui em favor da não condenação desse conflito epistemológico na medida em que nele reside o jogo de sentidos e a transformação em potencial no encontro entre professor-sujeito-intérprete e ILF-enquantosigno, de natureza refratária, dialogizante e heteroglóssica.

Palavras-chave: Inglês como Língua Franca; Currículo; Bakhtin; Conflito Epistemológico

Abstract: This paper aims at analysing the concept of English as a Lingua Franca (ELF) which underlies the English language guidelines in the National Common Core Curriculum Elementary Schools (BNCC). It starts with the presentation of the main definitions of such polemic and multivocal concept, with an emphasis on its first theorizations dated from the $80 \mathrm{~s}$ in international publications. More recent reconceptualizations of ELF in Brazil are brought to the fore as an attempt to spot what I have been calling here ELF made in Brazil from which emerges the very refractional, dialogic, and heteroglossic nature of words. The paper discusses such bakhtinian concepts followed by the analysis of the presence of ELF within the National Common Core Curriculum in which an epistemological conflict is identified as its introductory part seems to be in disagreement with the displayed content frames. Conflict arises inasmuch as the very fluid and situated nature of ELF collides with the normative and standardized status of a common core curriculum. Drawing on Bakhtinian thought, in particular, his notions of dialogism, refraction, and heteroglossia, the paper concludes in defense of this epistemological conflict insofar as the play of meanings along with its potential transformation resides from within such conflict in the very encounter between the teacher and ELF if assumed as refractional, dialogic, and heteroglossic sign.

Keywords: English as a Lingua Franca; Core Curriculum; Bakhtin; Epistemological Conflict 


\section{INTRODUÇÃO}

Neste artigo, busco analisar o conceito de inglês como língua franca (doravante ILF) que fundamenta o Componente Curricular Língua Inglesa da Base Nacional Comum Curricular - Ensino Fundamental (BNCC), apresentando alguns entendimentos que o conceito encerra. Antes, porém, de apresentá-los, quero já frisar que o conceito é polêmico e polissêmico, daqueles vocábulos que carregam o fardo do passado, como se tivesse sido duramente exposto a um ferro de marca gado, sempre às voltas com seu "sentido primeiro" após novos escrutínios e expansões teóricas.

A esse respeito, parece-nos oportuno recuperar a ideia de campo em Bourdieu (2004), entendido como sistema competitivo de relações sociais, cujos sujeitos participantes lutam ora pela preservação ora pela ruptura, num jogo de forças marcado pela não neutralidade e por relações desiguais de poder, a contento do quilate de cada capital (BOURDIEU, 1986, 1996). Daí vermos surgir, dentre outros fatores novas terminologias ${ }^{1}$ cunhadas por diferentes grupos de pesquisa, cujas bases epistemológicas ora se aproximam ora se colapsam. Concordo com Jordão (2014) quando a autora afirma que, ao invés de reduzir a questão à escolha de terminologias, deve-se investir na compreensão dos efeitos de sentido emergentes em dado campo.

Para além de tomar partido na relação dicotômica de amor e ódio que me parece estar fortemente presente no entorno do conceito de ILF, neste artigo proponho expor parte da teia complexa de sentidos emergentes que ora pendem para uma certa romantização ingênua do termo, ora pendem para um entendimento mais politizado. A polêmica ganha corpo quando o conceito passa a fundamentar o Componente Curricular Língua Inglesa da Base Nacional Comum Curricular (doravante BNCC), publicada em 2017, justamente por tornar ainda mais complexa a teia de sentidos na justaposição dos jogos de forças presentes tanto entre princípios correlatos e concorrentes no que concerne o inglês quanto entre as múltiplas vozes e tensões constituintes de uma política curricular dessa envergadura.

Para dar conta dessa empreitada, o artigo parte de um breve exercício genealógico do conceito de ILF, recuperando trabalhos pioneiros e contrapondo-os com teorizações mais contemporâneas, com ênfase para certas reconceituações no que chamo aqui ILF made in Brazil. Em seguida, o artigo se debruça na análise da presença do ILF na BNCC, subsidiandose nas noções bakhtinianas de refração, dialogismo e heteroglossia. $\mathrm{O}$ artigo finaliza em favor do conflito epistemológico ${ }^{2}$ em políticas curriculares como mola propulsora do jogo de sentidos e dos frutos que dele se pode colher na sala de aula de línguas.

\section{INGLÊS COMO LÍNGUA FRANCA: POLÊMICAS E POLISSEMIAS}

Os estudos sobre ILF datam da década de 80 com os trabalhos pioneiros de Jenkins (2000) e Seidlhofer (2001) quando passam a questionar a real utilidade do modelo do falante nativo em face da ruptura com a norma nos usos do inglês em contextos multilíngues. Assim é que a língua de contato e de escolha entre falantes de diferentes bagagens linguístico-culturais (JENKINS, 2009) necessitava ser pesquisada.

Àquela época, a preocupação se pautava no desejo de documentar os usos internacionais do inglês por meio da identificação de características essenciais do inglês tipicamente usado em seu status de língua franca, ou seja, como "língua de contato entre

\footnotetext{
${ }^{1}$ Este artigo versará mais detidamente sobre ILF. Para um aprofundamento acerca de outras terminologias circulantes do campo, recomendo o belíssimo artigo de Jordão (2014).

${ }^{2}$ De forma similar, Menezes de Sousa utilizou o termo colapso epistêmico em apresentação intitulada Language education policy and epistemological confrontation in Brazil proferida no $18^{\circ}$ Congresso Mundial de Linguística Aplicada (AILA), Rio de Janeiro, 2017.
} 
falantes cujas primeiras línguas diferiam" (JENKINS, 2006, p. 160). Assim é que, ao conceber ILF como um sistema adquirido adicionalmente com vistas à comunicação entre falantes de primeiras línguas distintas, Seidlhofer $(2001$, 2005) e seu grupo de pesquisas lançaram-se na empreitada da constituição de um corpus, o VOICE - Vienna-Oxford International Corpus of English ${ }^{3}$ - de modo a promover uma descrição empírica dos usos do inglês em contextos de comunicação internacional. Idealmente, a compilação do corpus serviria para subsidiar a reflexão e tomada de consciência com vistas à melhoria da negociação mútua ocorrida nessas situações comunicativas.

Essa empreitada investigativa de se compilar as características essenciais do inglês tipicamente usado em seu status de língua franca atrelada às definições supracitadas fizeram emergir no campo uma série de críticas ao termo. O'Regan (2014), por exemplo, denuncia duramente a falta de engajamento dos estudos de ILF com questões como discurso, poder e ideologia em sua reificação como um corpo de conhecimento que se pretende homogêneo sob uma pesquisa puramente descritiva, na medida em que a compilação de um corpus de ILF estabiliza e universaliza conteúdos linguísticos, ecoando uma visão estruturalista de língua que, segundo Friedrich e Matsuda (2010), teima em priorizar a forma no lugar da função social sob o risco de tornar ela mesma uma nova hierarquia do inglês.

Em solo brasileiro, também encontramos críticas ao conceito que parecem compactuar com esses apontamentos levando muitos colegas a um franzir de testas por conceberem ILF como projeto homogeneizante e normativo. Um exemplo é a compreensão de Tagata (2017) do termo língua "franca" como zona neutra e desinteressada ecoando, segundo Siqueira (2018a, p. 94), um entendimento de língua franca como “(...) zona franca comunicacional onde são travadas interações livres de impostos, neutras e desculturadas, levadas a cabo por uma espécie de língua 'descafeinada"”. Em nota de rodapé, Tagata (2017) se respalda ao esclarecer que parte do "sentido inicial e mais restrito do termo língua franca", o que corrobora o seu fardo semântico.

De fato, em publicação mais recente, a própria Jenkins (2015) faz menção às limitações de uma primeira fase dos estudos em ILF, reconhecendo que estes estiveram muito concentrados na identificação de um suposto corpus "internacional" e reconhecimento de aspectos linguísticos (no caso, pronúncia, léxico e gramática) com vistas a identificar quais elementos não afetavam a comunicação entre falantes de repertórios linguístico-culturais distintos. A mesma autora aponta que, ao final dos anos 2000, os estudos sobre ILF inauguram uma segunda fase em que se distanciam das pesquisas sobre World Englishes ao imprimir maior ênfase à fluidez e variabilidade do inglês usado em diferentes comunidades de prática, numa tentativa de desvincular o ILF de sua compreensão como mais uma "variação" (BAKER; JENKINS, 2015). Jenkins (2015) finaliza advogando em favor de uma terceira fase em que se passasse a conceber ILF como prática multilíngue, numa manobra discursiva que, a meu ver, demonstra uma tentativa do grupo em atualizar-se diante das recentes teorizações sobre linguagem, mobilidade e translinguismo.

Se essa expansão prometida na terceira fase irá vingar em pesquisas internacionais, não se sabe, pois ela é certamente tributária de uma ruptura ontológica e epistemológica. Seria leviano de minha parte afirmar que os atuais estudos sobre ILF conduzidos por pesquisadores de diversas partes do globo ainda estariam presos nessas primeiras fases. O fato é que parece haver ainda uma grande influência desses pilares na produção acadêmica sobre ILF.

Um exemplo consiste o estudo conduzido por Cogo e Dewey (2012) em que são apresentadas análises de "padrões" de ocorrências de ILF coletadas em corpora. Além da problemática menção a padrões, o esclarecimento conceitual trazido pelos autores é ainda permeado por categorias como círculo interno, círculo externo, círculo em expansão ${ }^{4}$, falantes

\footnotetext{
${ }^{3}$ Disponível em https://www.univie.ac.at/voice/page/what_is_voice. Acesso em 20 fev 2019.

${ }^{4}$ A nomenclatura se refere à teoria dos círculos concêntricos de Braj Kachru, de 1985, em que se estabelecem
} 
de primeira língua. Se de um lado há que se reconhecer o valor de um trabalho investigativo dessa envergadura, de outro tendo a acreditar que esses rastros e ranços dos estudos iniciais em estudos mais recentes acaba corroborando para a manutenção do fardo do passado às voltas com o "sentido primeiro".

Estudos que meramente constatam e documentam os usos alternativos do inglês não me parecem suficientes para o desenho de políticas linguísticas e educacionais afeitas à toda complexidade dos atuais encontros inter/transculturais. Nesse ponto, refrações de sentidos no entorno do ILF são bem-vindas, estão ocorrendo e devem ser disseminadas como exercício que põe em xeque o tal fardo semântico, numa tentativa de olhar para o termo sob rasura (DERRIDA, 2002[1967]). Se de um lado, há estudos priorizando uma pragmática ainda restrita à variação e mudança aos moldes de uma Sociolinguística embrionária, de outro há que se reconhecer a Co presença no campo de estudos mais atentos à compreensão dessas ocorrências de ILF sem desgrudar os olhos da intrínseca relação entre linguagem, política e poder.

Partilho aqui uma e outra refração na recente produção brasileira sobre ILF comparada à tradição dos estudos já instaurados no dito norte global de modo a dar visibilidade ao ILF made in Brazil. Sem qualquer pretensão de mapear quantitativamente toda a produção científica brasileira no entorno do conceito ${ }^{5}$, partilho apenas algumas problematizações emergentes, cujo teor já dá a ver um entendimento de ILF pautado noutras bases ontológicas e epistemológicas.

Inicio destacando o trabalho seminal do Prof. Rajagopalan (2005, 2010, 2011). Adepto do termo World Englishes, o pesquisador sábia e elegantemente não se enreda na paranoica e exaustiva aventura metalinguística de explicar sua preferência terminológica, concentrando forças naquilo que realmente interessa: a problematização do status do inglês na contemporaneidade colada à natureza política da linguagem. Rajagopalan (2005) advoga em favor da ruptura do tratamento prioritário e dicotômico por vezes atribuído às noções como falante nativo e não nativo, primeira língua e língua estrangeira, dentre outras, por já não darem conta das novas complexidades da sociedade pós-moderna. O pesquisador (2010) traz ainda uma rica reflexão acerca dos conceitos de comunicação e inteligibilidade, em que afirma não bastar apenas reconhecer quem está e quem não está autorizado a comunicar-se em contexto de ILF muito menos que elementos linguísticos garantiriam ou não a comunicação entre falantes. Como se pode ver, o teor dessa discussão mexe com as ontologias e epistemologias ao tratar de sujeito, identidade, cultura, língua.

Outros estudos made in Brazil são merecedores dos holofotes, pois trazem um olhar crítico e transdisciplinar para o ILF por vezes ausente em outros loci. Zacchi (2018), por exemplo, parte da tríade colonialismo, imperialismo e capitalismo de Walter Mignolo para promover a crítica ao viés globalizante naturalmente atribuído ao conceito de ILF e propõe que discussões acerca de cosmopolitismo subalterno e letramentos transnacionais sejam incorporados ao debate por estes se voltarem a práticas de linguagem situadas, num

três círculos nos quais se inscrevem três tipos de falante do inglês em conformidade com a delimitação territorial: o círculo interno corresponde aos países onde o inglês é a primeira língua (como Estados Unidos e Inglaterra); o círculo externo ou estendido se refere aos países onde o inglês funciona como segunda língua, usualmente em contextos multilíngues (como Índia); já os círculos em expansão se referem aos países onde o inglês é ensinado como língua estrangeira (como China, Rússia, Brasil). A teoria dos círculos concêntricos influenciou enormemente o campo, mas já foi extensamente revisitada diante dos atuais processos de globalização e da desterritorialização do inglês.

${ }^{5}$ Os mapeamentos realizados por Calvo e El Kadri (2011) e Bordini e Gimenez (2014) atestam para relativa escassez de estudos em solo brasileiro entre 2005 e 2012, sinalizando, porém, um aumento de publicações a partir de 2011. O trabalho de Bordini e Gimenez (2014), em particular, constata a ausência de pesquisas empíricas de interações envolvendo brasileiros, o que incorre na dependência da literatura internacional. 
movimento que abre o diálogo com as epistemologias do sul.

Com base nas contribuições dos estudos sobre letramento crítico, pós-estruturalismo e pós-humanismo, Jordão e Marques (2018), por sua vez, discutem ILF partindo da valorização do contexto, da contingência e dos usos locais da linguagem. Os autores trazem uma dura crítica à suposta neutralidade com que as interações em ILF são tratadas, como se estas fossem imunes a implicações político-ideológicas e advogam em defesa de um exercício de descolonização do ILF no ensino de inglês e na formação docente.

Em tom similar, Duboc (2018) denuncia a ideia ainda restrita do conceito de comunicação em muitos estudos sobre ILF, o risco iminente das generalizações no entorno do malfadado conceito de nativeness e ainda uma certa visão romântica, acrítica e apolítica que permeia algumas discussões sobre ILF no âmbito internacional. Em resposta a essas limitações, a autora articula contribuições do pensamento pós-moderno aos estudos de ILF para repensar a formação docente contemporânea.

Educação intercultural é aspecto em foco nas teorizações sobre ILF em Siqueira (2011, 2018b). Corroborando Jordão e Marques (2018), o autor advoga em favor da descolonização do currículo, de materiais didáticos plastificados e de práticas escolares arraigadas em premissas, conceitos, estratégias e ferramentas do mainstream. $\mathrm{O}$ autor (2018a), advoga em favor de uma agenda politizada do ILF, passando a compreendê-lo como espaço de descolonialidade e de acolhida às práticas translíngues.

Essa seção assumiu o desafio de recuperar, brevemente, a gênese dos estudos de ILF em âmbito internacional para culminar nos sentidos recentemente atribuídos ao termo em solo brasileiro. Para tanto, optou por priorizar o trabalho seminal de importantes agentes do campo - Jennifer Jenkins e Barbara Seidlhofer - justamente por entender que foram esses "primeiros sentidos" e essas primeiras ações investigativas que deram o tom às pesquisas subsequentes. O resultado de tamanha influência é evidenciado num conjunto de críticas ao termo, em que se denuncia uma suposta reificação articulada à ausência de análises mais políticas. Ao partilhar novas reconceituações made in Brazil que se contrapõem, em certa medida, a um entendimento mais hermético do termo, atesto aqui a natureza refratária, dialogizante e heteroglóssica do signo bakhtiniano, como discuto na seção subsequente, para, então, voltarme mais detidamente ao conceito de ILF na BNCC, objetivo central deste artigo.

\section{REFRAÇÃO, DIALOGISMO E HETEROGLOSSIA EM BAKHTIN}

Bakhtin dispensa apresentações. É inegável a contribuição significativa que suas teorizações trouxeram para os estudos da linguagem ao longo dos últimos anos. Neste artigo, tratarei especificamente dos conceitos que me parecem caros à temática aqui posta, quais sejam, refração, dialogismo e heteroglossia.

O tripé aqui eleito parte, de forma coesa, da visão bakhtiniana de língua como prática social e de seu entendimento de signo como elemento ideológico. Sob influência do marxismo, Bakhtin prima pela enunciação e, ao fazê-lo, incute no processo interpretativo um elemento fundamental: a história, os sujeitos que nela se inscrevem e as ideologias que a permeiam. Com isso, o texto passa de objeto reificado passível de uma dissecação mecanicista de sentidos - como quer o estruturalismo - a enunciado vivo, pulsante, dinâmico: "Não há textos puros. Nem poderia haver", afirma Bakhtin (1997[1979], p. 331). Assim é que, ao compreender texto como enunciado, Bakhtin refuta a ideia mesma de representação, apostando as fichas em sua natureza fronteiriça e dialógica, num movimento que torna o texto sempre novo: "Ver uma coisa, tomar consciência dela pela primeira vez, significa estabelecer uma relação dialógica com a coisa: ela não existe mais só em si e para si, mas para algum outro (já há uma relação de duas consciências)" (ibid., p. 343).

Bakthin (ibid., p. 351) complexifica a questão ao propor uma tríade viva em que "A 
relação com o enunciado do outro não pode ser separada nem da relação com a coisa (que é objeto de uma discussão, de uma concordância, de um encontro), nem da relação com o próprio locutor". Nesse sentido, continua o filósofo (ibid., p. 352),

\begin{abstract}
os valores do enunciado não se determinam por sua relação com a língua (enquanto sistema), mas pelas formas de sua relação com a realidade, com o sujeito falante, com os outros enunciados - com os enunciados alheios - (em particular com aqueles que os colocam como valores da verdade, da beleza etc).
\end{abstract}

Sob esse entendimento de texto como enunciação, o dialogismo torna-se, portanto, peça-chave para uma teoria da interpretação à moda bakhtiniana, pois é justamente no encontro entre palavra e sujeito-intérprete inscrito socioculturalmente que reside o sentido. Assim discorre Bakhtin (ibid., p. 345): “A relação dialógica pressupõe uma língua, mas não existe no sistema da língua. Não pode estabelecer-se entre os elementos da língua. (...) A relação dialógica é uma relação (de sentido) que se estabelece entre enunciados na comunicação verbal". Para além da palavra como mera materialidade, trata-se aqui da palavra como signo ideológico, historicamente situada e potentemente hospedeira de uma multiplicidade de sentidos.

O conceito de signo dialógico em Bakhtin prevê, assim, um exercício de refração de sentidos. Ao condenar a reificação do signo e tratar das possibilidades e perspectivas infinitas que estariam latentes na palavra, o filósofo (ibid., p. 348) refuta a ideia de reflexo e dá as boas-vindas à natureza refratária do signo:

\begin{abstract}
O enunciado nunca é simples reflexo ou expressão de algo que lhe preexistisse, fora dele, dado e pronto. O enunciado sempre cria algo que, antes dele, nunca existira, algo novo e irreproduzível, algo que está sempre relacionado com um valor (a verdade, o bem, a beleza, etc.). Entretanto, qualquer coisa criada se cria sempre a partir de uma coisa que é dada (a língua, o fenômeno observado na realidade, o sentimento vivido, o próprio sujeito falante, o que é já concluído em sua visão de mundo etc). $\mathrm{O}$ dado se transfigura no criado.
\end{abstract}

Ao tratar do caráter deformador do signo, Bakhtin/Volochinov (2004[1929], p. 46) incutem ao movimento de refração o jogo de interesses sociais. Se em Marxismo e filosofia da linguagem, publicado em 1929, esse jogo é fortemente marcado pelo discurso da luta de classes, aqui, parece-me mais oportuno trazer à baila a ideia das forças centrípeta e centrífuga discutidas em Dialogic Imagination, de 1975.

Nessa obra, o filósofo (1981[1975]) destrona a poesia de seu pedestal ao legitimar a pluralidade linguística da prosa, que, de natureza dialogizante, ecoa a multiplicidade de vozes, a heteroglossia da linguagem, por assim dizer. Para Bakhtin, a poesia é gênero hermeticamente fechado, centralizador, normatizador, que se pretende unívoco, enquanto a prosa é gênero solto, descentrado, plástico, de cuja materialidade brotam as múltiplas vozes inerentes à linguagem. Assim é que operam duas forças em constante embate na linguagem: de um lado forças centrípetas que visam regular, normatizar, centralizar uma estrutura com vistas a uma suposta língua unitária, e, de outro, forças centrífugas que teimam em descentrar a norma, fazendo aflorar a criatividade e a pluralidade linguística. É a heteroglossia dialogizante da linguagem em oposição ao cânone, à norma-padrão, ao pretenso projeto do monolinguismo.

Em outras palavras, a heteroglossia surge como o discurso de outrem na língua de outrem encerrando uma autoria já refratada. Trata-se, pois, do entrelaçamento de múltiplas vozes ou perspectivas individuais e sociais, atestando para o fato de que ninguém é autor da palavra proferida (exceto Adão, como o próprio Bakhtin ressalta). Em termos derrideanos, não existe a presença ou origem, o tal sentido primeiro; a linguagem é toda tecida via 
suplemento, em que o signo, sob rasura, encontra-se em estado de différance, duplamente marcado pela diferença que o caracteriza em dada estruturalidade e pelo adiamento e imprevisibilidade de seu sentido no porvir (DERRIDA, 2002[1967]). Diante dessas considerações, debruço-me, na seção seguinte, sobre o conceito de ILF para analisar sua presença na BNCC à luz do pensamento bakhtiniano. Antes, porém, termino a seção com um belíssimo excerto em que o filósofo (1981[1975], p. 292) desnuda os nocivos efeitos de se negligenciar a natureza refratária, dialogizante e heteroglóssica da palavra:

O discurso vive, por assim dizer, além de si mesmo, num impulso vivo [napravlennost'] em direção ao objeto; se nos separarmos completamente desse impulso, tudo o que nos resta é o corpo despido da palavra, do qual não podemos aprender nada sobre a situação social ou o destino de uma dada palavra na vida. Estudar a palavra sob tal visão, ignorando o impulso que extrapola, é tão sem sentido quanto estudar a experiência psicológica fora do contexto daquela vida real para a qual ela foi dirigida e pela qual ela é determinada.

\section{O CONCEITO DE ILF NO COMPONENTE CURRICULAR LÍNGUA INGLESA DA BNCC}

O ensino de inglês no Brasil é marcado historicamente por um discurso de fracasso já denunciado por pesquisadores brasileiros (ASSIS-PETERSON, COX, 2013; DUBOC, 2018; DUBOC, GARCIA, RODRIGUES, 2018; SIQUEIRA, DOS ANJOS, 2012 dentre outros). Um dos fatores relacionados a esse discurso se refere ao ranço colonialista do inglês e a empreitada árdua de muitos brasileiros na busca idealizada do "domínio" do idioma, calcado em preceitos como precisão, pureza e imitação do falante nativo.

Considerando que o conceito de ILF caiu praticamente de paraquedas no Componente Curricular Língua inglesa da BNCC (BRASIL, 2017) e tendo em vista que é praticamente nula a discussão sobre o conceito de ILF na formação docente inicial e continuada (GIMENEZ, EL KADRI, CALVO, 2018; COGO, SIQUEIRA, 2017), essa seção busca analisar partes do componente com um duplo propósito: i) contribuir para a expansão de perspectivas do professor de inglês em formação e em serviço no que diz respeito ao conceito de ILF; ii) contribuir para o debate sobre os sentidos de ILF junto a pesquisadores e formadores de professores, posto que o conceito é escorregadio e tem causado certo barulho no campo, dado o conflito epistemológico que emerge da natureza fluida e situada em certo entendimento de ILF em colapso com a normatividade e padronização de um currículo nacional comum.

Não pretendo lançar-me a uma análise detalhada acerca do componente curricular; tampouco detalharei questões atinentes ao campo curricular - campo, vale dizer, não menos escorregadio (LOPES; MACEDO, 2011). O propósito da seção consiste em partilhar com o leitor de que maneira as minhas leituras sobre os vários sentidos de ILF - como apresentado na primeira seção - somadas às contribuições de Bakhtin - resumidas na segunda seção inspiram-me a ler a presença do ILF na BNCC de forma ventilada, em favor de um novo olhar para o entendimento da própria noção de conflito.

Todo componente curricular da BNCC inicia com um texto introdutório o qual culmina na apresentação das competências específicas. Posteriormente, são apresentados quadros didáticos que organizam as unidades temáticas, os objetos de conhecimento e as habilidades $^{6}$ a serem cumpridas ano a ano ao longo do Ensino Fundamental. No caso do Componente Curricular Língua Inglesa - aliás, componente que, lamentavelmente, evidencia

\footnotetext{
${ }^{6}$ Para maior esclarecimento quanto à estrutura da BNCC, recomendo acessar o documento na íntegra disponível em http://basenacionalcomum.mec.gov.br/. Acesso em 25 fev 2019.
} 
uma orientação monolíngue ao substituir as chamadas LEM (Línguas Estrangeiras Modernas) - o texto introdutório resgata o caráter formativo da língua inglesa no currículo escolar, atribuindo-lhe importante papel no engajamento discursivo do aluno em um mundo globalizado. Na introdução, é valorizada a função social e política da língua, expandindo-se, num primeiro olhar, para além da função tecnicista e instrumental por vezes atribuída à língua estrangeira. $\mathrm{O}$ texto traz conceitos pertinentes e extremamente atuais, como a desterritorialização do inglês, as limitações da orientação eurocêntrica que permeia os estudos da língua e a necessidade de romper com o modelo do falante nativo e repensar conceitos como correção, precisão e proficiência.

Todo esse rol de vocábulos fresquinhos se orquestra com vistas a justificar a adoção do termo língua franca, definida no documento como "uma língua que se materializa em usos híbridos, marcada pela fluidez e que se abre para a invenção de novas formas de dizer, impulsionada por falantes pluri/multilíngues e suas características multiculturais" (BRASIL, 2017, p. 240). Articula ainda o conceito de ILF à ideia de educação linguística para a interculturalidade, dando as boas-vindas à "reflexão crítica sobre diferentes modos de ver e analisar o mundo, o(s) outro(s) e a si mesmo" (ibid., p. 240). Em termos metodológicos, o texto introdutório afirma ser fundamental que o professor assuma uma "atitude de acolhimento e legitimação de diferentes formas de expressão na língua” (ibid., p. 240). Sob a difícil tarefa de não trazer explicitamente referencial teórico no corpo do texto, o documento revela sua heteroglossia na medida em que logo aqui, na introdução, é possível reconhecer as múltiplas vozes que vem atuando nos estudos de ILF.

Se de um lado as considerações tecidas no texto introdutório coadunam-se com conceitos e categorias pertinentes para o repensar do status do inglês na contemporaneidade, de outro, a análise dos quadros didáticos dispostos ano a ano evidenciam, paradoxalmente, lapsos de engessamento de conteúdos, ecoando - ainda que o documento se coloque afeito a um desenho curricular espiralado - um discurso atualizado que camufla conteúdos de língua tradicionalmente ensinados numa lógica de linearidade e hierarquização (Simple Present no $6^{\circ}$ ano > Simple Past no $7^{\circ}$ ano > Future Forms no $8^{\circ}$ ano). Eis o conflito epistemológico: como pode um documento acolher os usos criativos, híbridos e locais do inglês em seu status de língua franca se o próprio documento organiza, linear e hierarquicamente, temas, objetos de conhecimento e habilidades, com exemplos de conteúdos linguísticos fixos e estáveis? A título de ilustração, trago abaixo um desses quadros:

Figura 1: Quadro extraído do Componente Curricular Língua Inglesa da BNCC

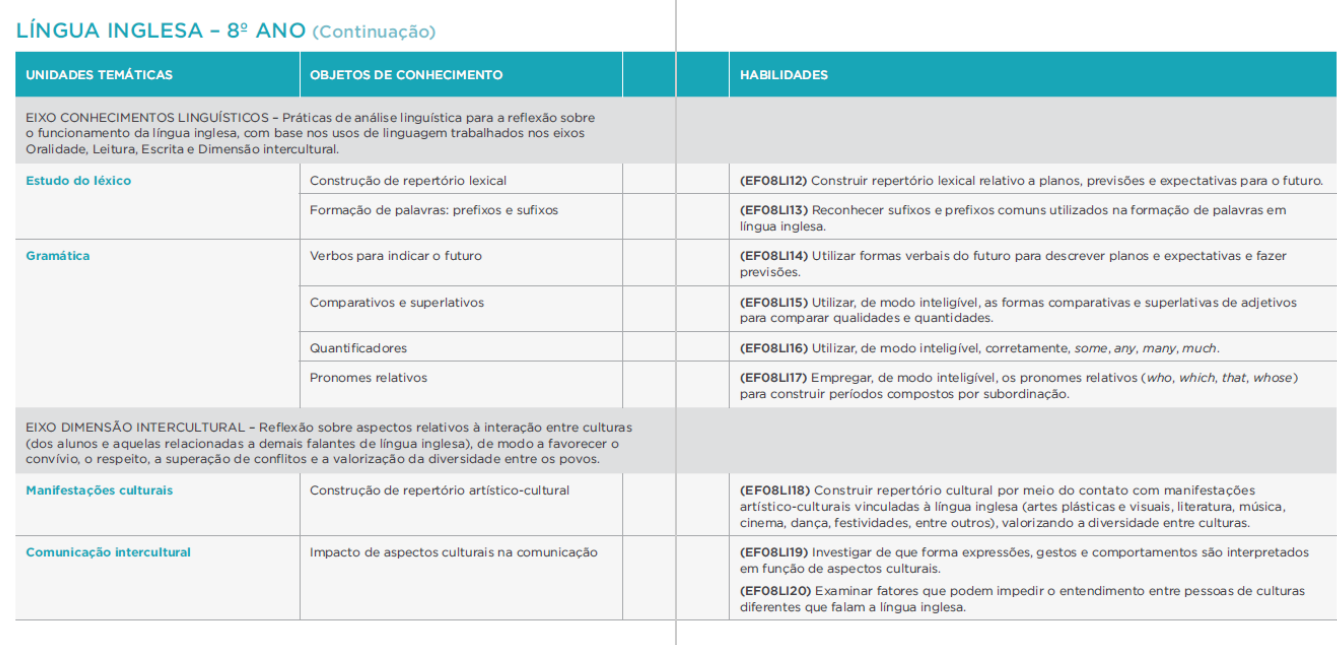

Fonte: (Brasil, 2017: 259) 
A apropriação discursiva mais fluida prometida na introdução - como o conceito de inteligibilidade em oposição à ideia de proficiência - aparece, contraditoriamente, ao lado do conceito de correção em algumas habilidades do eixo Conhecimentos Linguísticos. Ora, se levado a cabo o status do inglês em sua condição como língua franca nas situações comunicativas no espaço escolar como quer o texto introdutório, conteúdos linguísticos dispostos no quadro (como some, any, many, much na habilidade de código EF08LI16) não poderiam ser delimitados previamente sob uma compreensão do ILF que o distancia de sistema ou variação; ILF, segundo Jordão e Marques (2018), é o inglês em status de língua franca usado por usuários de diferentes repertórios linguístico-culturais em práticas contextualizadas. Sob esse entendimento, o ILF, quando pensado em contextos educacionais, refuta qualquer pretensão de se impor o que deve e o que não deve ser ensinado na aula de inglês (COGO E SIQUEIRA, 2017). Afeitos a uma atitude pós-normativa, Jordão e Marques (2018, p. 58) afirmam que, sob a perspectiva do ILF, deve-se mudar o foco em regras gramaticais institucionalizadas para o encorajamento da negociação entre as diversas gramáticas e repertórios linguístico-culturais que emergem das situações comunicativas em inglês.

Termino a seção com alguns questionamentos que brotam daquilo que ancora a ideia mesma do conflito epistemológico: o jogo entre fluidez, performance, localismos e estabilidade, normatividade, padronização. Diante de uma base nacional comum curricular:

i. Qual o espaço para que o professor de inglês priorize o contexto, a contingência e a imprevisibilidade segundo informam alguns dos entendimentos de ILF made in Brazil já refratados?

ii. Qual o espaço para que o professor de inglês faça jus à negociação de sentidos que emergem dos usos locais da língua quando esta é entendida como discurso ou acontecimento e não como sistema?

iii. Qual o espaço para que o professor de inglês desenvolva o exercício genealógico com vistas à descolonização de ideias, premissas, valores, perspectivas e práticas no que diz respeito ao status do inglês contemporâneo?

\section{E VIVA A LÍNGUA REFRATÁRIA, DIALOGIZANTE E HETEROGLÓSSICA: DO CONFLITO SE FAZ AGÊNCIA!}

Este artigo buscou analisar o conceito de inglês como língua franca (ILF) que fundamenta o Componente Curricular Língua Inglesa da BNCC. Para tanto, os primeiros entendimentos deste conceito polêmico e polissêmico foram confrontados com reconceituações mais recentes, priorizando-se o debate em solo brasileiro por sua fértil problematização de natureza crítica e política. O fardo semântico por vezes atribuído a certas palavras passa, então, a ser relativizado na constatação da natureza refratária, dialogizante e heteroglóssica da linguagem, segundo Bakhtin, levando-me a compreender o conflito epistemológico posto na presença do ILF em uma base nacional comum curricular de forma mais ventilada.

Retomo os questionamentos postos na seção anterior no intuito de respondê-los à moda bakhtiniana: os espaços localizam-se, justamente, na natureza fronteiriça deste texto chamado BNCC; os espaços constituem os interstícios entre o professor-sujeito-intérprete que, inscrito socioculturalmente, lê a palavra inscrita na BNCC, mas a lê de modo a estabelecer uma relação dialógica com a mesma nunca em relação ao acrônimo per se, mas sempre na relação com os diferentes loci de enunciação onde ILF circula. Não a palavra reificada, mas a palavra potente que acolhe um exercício hermenêutico que não franze a testa para as refrações de sentidos possíveis pela própria natureza dialogizante do signo; tampouco 
franze a testa para a heteroglossia pulsante no todo do documento, em que diferentes vozes situadas em diferentes loci podem ali ser rastreadas, num movimento que desvelaria forças centrípetas e forças centrífugas atuantes em políticas curriculares: de um lado, discursos inovadores que desejam romper com o mainstream; de outro, escolhas discursivas que escorregam contraditoriamente num discurso hegemônico.

Para os adeptos do conceito de ILF, trata-se de olhar positivamente para sua presença na BNCC, na medida em que, ainda que os quadros revelem as "escorregadas", muitos dos preceitos trazidos no texto introdutório são merecedores do reconhecimento quanto à tentativa de romper com práticas convencionais. Já para os críticos ferrenhos do conceito, a presença do ILF na BNCC cai como uma luva por atestar, de certa maneira, a velha crítica do ILF como projeto homogeneizante e normativo. Ao que tudo indica, o ILF, a exemplo do pharmakon (DERRIDA, 2005[1985]), é veneno e remédio, a depender de quem o concebe, como o concebe, como se relaciona com os demais agentes do campo e em que bases ontológicas e epistemológicas se ancora.

Concluo este artigo em favor da não condenação do conflito epistemológico evidenciado na presença do ILF na BNCC na medida em que nele reside justamente o jogo de sentidos do professor-sujeito-intérprete no encontro com o ILF-enquanto-signo. É a própria natureza refratária, dialogizante e heteroglóssica da palavra que permite preservação e ruptura nos espaços de manobra (MORGAN, 2010) ou brechas (DUBOC, 2015) da sala de aula. É provável que muitos professores ignorem as potentes fissuras do conceito de ILF no texto introdutório da BNCC e transformem os quadros didáticos em seu porto-seguro; como também é provável que muitos professores ignorem os conteúdos lá dispostos para, no final do dia, ensinar o "inglês que cada um pode" (JORDÃO; MARQUES, 2017). Se esse for o caso, então a presença do ILF, fundamentando, pela primeira vez, um documento regulador da Educação Básica, vem coroar a falácia e o mito do inglês puro e idealizado pretendido historicamente em propostas curriculares e materiais didáticos.

\section{Referências}

ASSIS-PETERSON, A. A; COX, M. I. P. Standard English \& World English: entre o siso e o riso. Calidoscópio. v.11, n. 2, p. 153-166, 2013.

BAKER, W.; JENKINS, J. Criticising ELF. JELF. v. 4, n. 1, p.191-198, 2015.

BAKHTIN, M. M. The dialogic imagination: four essays. Austin and London: University of Texas Press, 1981[1975].

BAKHTIN, M. M. Estética da criação verbal. São Paulo: Martins Fontes, 1997[1979].

BAKHTIN, M. M. / VOLOCHINOV, V. N. Marxismo e filosofia da linguagem. São Paulo: Hucitec, 2004[1929].

BORDINI, M.; GIMENEZ, T. Estudos sobre Inglês como Língua Franca no Brasil (20052012): uma metassíntese qualitativa. SIGNUM: Estud. Ling. Londrina, v. 17, n. 1, p. 10-43, jun. 2014.

BRASIL. Base Nacional Comum Curricular. Brasília: Ministério da Educação/Secretaria da Educação Básica, 2017. 
BOURDIEU, P. "The Forms of Capital”. In: RICHARDSON, J. (Ed.). Handbook of Theory and Research for the Sociology of Education. New York: Greenwood, 1986. p. 241-258.

BOURDIEU, P. Razões práticas: sobre a teoria da ação. Campinas: Papirus, 1996.

BOURDIEU, P. Os usos sociais da ciência: por uma sociologia clínica do campo científico. São Paulo: Editora UNESP, 2004.

CALVO, L. C. S, EL KADRI, M. S. "Mapeamento de estudos nacionais sobre inglês como língua franca: lacunas e avanços". In: GIMENEZ, T.; CALVO, L.C.S.; EL KADRI, M.S. (Orgs.) Inglês como lingua franca: ensino-aprendizagem e formação de professores. Campinas: Pontes Editores, 2011. p.17-44.

COGO, A.; DEWEY, M. Analysing English as a Lingua Franca: A Corpus-Driven Investigation. New York: Continuum, 2012.

COGO, A.; SIQUEIRA, S. Emancipating myself, the students and the language: Brazilian teachers' attitudes towards ELF and the diversity of English Englishes. Practice. v. 4, n. 3, p. 50-78, 2017.

DERRIDA, J. A escritura e a diferença. São Paulo: Perspectiva, 2002[1967]

DERRIDA, J. A Farmácia de Platão. São Paulo: Iluminuras, 2005[1985]

DUBOC, A. P. M. Atitude Curricular: Letramentos Críticos nas Brechas da Sala de Aula de Línguas Estrangeiras. 1. ed. Jundiaí: Paco Editorial, 2015. v. 1. 304p.

DUBOC, A. P. M. "The ELF teacher education: contributions from postmodern perspectives". In: GIMENEZ, Telma; EL KADRI, Michelle Salles; CALVO, Luciana Cabrini Simões. (Org.). English as a lingua franca in teacher education: a Brazilian perspective. 1ed.Berlin/Boston: De Gruyter, 2018, v. 10, p. 159-188.

DUBOC, A. P. M.; GARCIA, B.; RODRIGUES, L. A. D. "Collaborative Curriculum Design under an ELF Perspective: An Innovative Experience in Southern Brazil Municipal Schools". In: MARTIN-RUBIÓ, Xavier. (Org.). Contextualising English as a Lingua Franca: From Data to Insights. 1ed.Newcastle: Cambridge Scholars Publishing, 2018, v. 1, p. 229-250.

FRIEDRICH, P.; MATSUDA, A. When Five Words Are Not Enough: A Conceptual and Terminological Discussion of English as a Lingua Franca. International Multilingual Research Journal. v. 4, p. 20-30, 2010.

GIMENEZ, M. S. EL KADRI, L. C. S. CALVO. (Org.). English as a lingua franca in teacher education: a Brazilian perspective. Berlin/Boston: De Gruyter, 2018.

JENKINS, J. The phonology of English as an international language. United Kingdom: Oxford University Press, 2000.

JENKINS, J. Current Perspectives on Teaching World Englishes and English as a Lingua Franca. TESOL QUARTERLY, v. 40, n. 1, p.157-181, 2006. 
JENKINS, J. English as a lingua franca: interpretations and attitudes. World Englishes, v. 28, n. 2, p. 200-207, 2009.

JENKINS, J. Repositioning English and multilingualism in English as a Lingua Franca. Englishes in Practice, v. 2, n. 3, p. 49-85, 2015.

JORDAO, C. M. ILA - ILF - ILE - ILG: Quem dá conta? RBLA. v. 14, n. 1, p. 13-40, 2014.

JORDÃO. C. M.; MARQUES, A. N. "English as a Lingua Franca and critical literacy in teacher Education: Shaking off some 'good old' habits". In: T. GIMENEZ, M. S. EL KADRI, L. C. S. CALVO. (Org.). English as a lingua franca in teacher education: a brazilian perspective. Berlin/Boston: De Gruyter, 2018, v. 10, p. 53-68.

LOPES, A. C.; MACEDO, E. "Contribuições de Stephen Ball para o estudo de políticas de currículo". In: BALL, S.; MAINARDES, J. (Orgs.). Políticas educacionais: questões e dilemas. São Paulo: Cortez, 2011.

MORGAN, B. Fostering conceptual roles for change: identity and agency in ESEA teacher preparation. Kritika Kultura, Manila, v. 15, n. 15, p. 34-55, 2010.

O'REGAN, J. English as a lingua franca: An immanent critique. Applied Linguistics. v. 35, n. 5, p. 533-552, 2014.

RAJAGOPALAN, K. Postcolonial world and Postmodern identity: some implications for language teaching. D.E.L.T.A. v. 21, Especial, p. 11-20, 2005.

RAJAGOPALAN, K. The rigmarole of intelligibility in world english(es) - or, on making sense of it all or, if you like, making the very idea of intelligibility intelligible. $R$. Let. \& Let. Uberlândia, v. 26, n. 2, p. 477-492, 2010.

RAJAGOPALAN, K. "O 'World English': um fenômeno muito mal compreendido". In: GIMENEZ, T.; CALVO, L.C.S.; EL KADRI, M.S. (Orgs.) Inglês como lingua franca: ensino-aprendizagem e formação de professores. Campinas: Pontes Editores. 2011, p. 45-58.

SEIDLHOFER, B. Closing a conceptual gap: the case for a description of English as a lingua franca. International Journal of Applied Linguistics. v. 11, n. 2, p. 133-158, 2001.

SEIDLHOFER, B. English as a lingua franca. ELT Journal. v. 59, n. 4, p. 339-341, 2005.

SIQUEIRA, D. S. P. "Inglês como língua franca: O desafio de ensinar um idioma desterritorializado". In: GIMENEZ, T.; CALVO, L.C.S.; EL KADRI, M.S. (Orgs.) Inglês como lingua franca: ensino-aprendizagem e formação de professores. Campinas: Pontes Editores, 2011, p. 87-116.

SIQUEIRA, D. S. P.; DOS ANJOS, F. A. Ensino de inglês como língua franca na escola pública: por uma crença no seu (bom) funcionamento. Muitas Vozes. Ponta Grossa, v. 1, n. 1, p. 127-149, 2012.

SIQUEIRA, S. "English as a Lingua Franca and teacher education: Critical educators for an intercultural world". In: T. GIMENEZ, M. S. EL KADRI, L. C. S. CALVO. (Org.). English 
as a lingua franca in teacher education: a brazilian perspective. Berlin/Boston: De Gruyter, v. 10, p. 87-114. 2018a.

SIQUEIRA, S. Inglês como Língua Franca Não é Zona Neutra, é Zona Transcultural de Poder: Por Uma Descolonização de Concepções, Práticas e Atitudes. Línguas \& letras. v.19, n. 14, p. $93-113,2018 b$.

TAGATA, W. M. Letramento crítico, ética e ensino de língua inglesa no século XXI: por um diálogo entre culturas. RBLA, v. 17, n.3, p. 379-403, 2017.

ZACCHI, V. "Global Englishes, local histories". In: T. GIMENEZ, M. S. EL KADRI, L. C. S. CALVO. (Org.). English as a lingua franca in teacher education: a brazilian perspective. Berlin/Boston: De Gruyter, v. 10, p. 13-30, 2018.

Ana Paula Martinez Duboc anaduboc@usp.br

Recebido em: 28 fev. 2019 Aceito em: 03 abril. 2019

Publicado em: Junho 2019 